\title{
Adjustable inspiratory occlusion valve in experimental bronchopleural fistula. A new therapeutic perspective ${ }^{1}$
}

\author{
Maria Gabriela Cavicchia Toneloto ${ }^{\mathrm{I}}$, Marcos Mello Moreira ${ }^{\mathrm{II}}$, Joaquim Murray Bustorff-Silva ${ }^{\mathrm{III}}$, Gabriel Franco de Souza ${ }^{\mathrm{IV}}$, \\ Luiz Claudio Martins", Desanka Dragosavac ${ }^{\text {VI }}$, Antonio Luis Eiras Falcão ${ }^{\text {II }}$ \\ DOI: http://dx.doi.org/10.1590/S0102-865020150080000007 \\ IPhD, Full Professor, Division of Pneumology, Department of Physical Therapy, Universidade de Jaguariúna (FAJ), Brazil. Design of the study, \\ technical procedures, manuscript writing, supervised all phases of the study. \\ IIPhD, Division of Pneumology, Department of Internal Medicine, Faculty of Medical School, Universidade de Campinas (UNICAMP), Brazil. \\ Designed of the study, technical procedures, acquisition and interpretation of data. \\ IIIPhD, Full Professor, Division of Pediatric Surgery, Department of Surgery, Medical School, UNICAMP, Campinas-SP, Brazil. Technical procedures, \\ acquisition and interpretation of data.

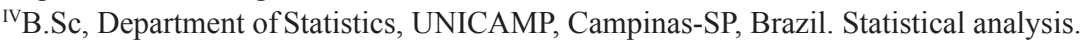 \\ ${ }^{v} \mathrm{PhD}$, Physician Assistant, Division of Physiology and Metabology in Surgery, Department of Surgery, Medical School, UNICAMP, Campinas-SP, \\ Brazil. Design of the study, technical procedures, acquisition and interpretation of data. \\ ${ }^{V} \mathrm{PhD}$, Full Professor, Division of Physiology and Metabology in Surgery, Department of Surgery, Medical School, UNICAMP, Campinas-SP, Brazil. \\ Design of the study, technical procedures, acquisition and interpretation of data.
}

\begin{abstract}
PURPOSE: To assess the efficacy of an adjustable inspiratory occlusion valve in experimental bronchopleural fistula during mechanical ventilation.

METHODS: We studied six mechanically ventilated pigs in a surgically created, reproducible model of bronchopleural fistula managed with mechanical ventilation and water-sealed thoracic drainage. An adjustable inspiratory occlusion valve was placed between the thoracic drain and the endotracheal tube. Hemodynamic data, capnography and blood gases were recorded before and after the creation of the bronchopleural fistula as well as after every adjustment of the inspiratory occlusion valve.

RESULTS: When compared with the standard water-sealed drainage treatment, the use of an adjustable inspiratory occlusion valve improved the alveolar tidal volume and reduced bronchopleural air leak $(\mathrm{p}<0.001)$, without hemodynamic compromise when compared with conventional water sealed drainage.

CONCLUSION: The use of an adjustable inspiratory occlusion valve improved the alveolar tidal volume, reduced alveolar leak, in an experimental reproducible model of bronchopleural fistula, without causing any hemodynamic derangements when compared with conventional water sealed drainage.
\end{abstract}

Key words: Fistula. Respiration, Artificial. Capnography. Models, Animal. Swine. 


\section{Introduction}

A bronchopleural fistula (BPF) is a condition that has high mortality rate especially when associated with invasive mechanical ventilation (MV). It manifests initially by pneumothorax and, after the installation of adequate chest tube drainage, by air leakage from the airway to the outside ${ }^{1}$. The diagnosis of BPF is established when air leak through the chest tube persists for at least 24 hours ${ }^{2,3}$.

The etiology of BPF is multifactorial and may result from pneumonia, radiotherapy, chemotherapy, tumors, tuberculosis, pulmonary resection surgery, chest trauma, ARDS and, in Intensive Care Units (ICUs), it is often associated with barotrauma and $\mathrm{MV}^{4,5}$. Whatever the cause, BPF is difficult to treat, considering that the patients receive positive pressure, which tends to hinder closure of the fistula. Significant air leakage results in high morbidity and the mortality rate of $18 \%$ to $50 \%$,

Patients with BPF may significantly worsen the ventilation/ perfusion balance and arterial blood gases. BPF causes well described changes such as leakage of gases, reduction of the airway pressure, reduced alveolar ventilation per minute, alveolar collapse, arterial hypoxemia, respiratory acidosis, barotrauma or volutrauma in the contralateral lung as a complication of $\mathrm{MV}$, difficulty in maintaining the positive end-expiratory pressure (PEEP) and self-cycling ${ }^{4,7}$.

The success in handling BPF depends on treatment strategies, tailored according to individual needs of patients. The conventional treatment consists of organ support, intercostal catheters, chest drainage and MV and surgical or bronchoscopic definitive therapies ${ }^{4}$.

Since the $70 \mathrm{~s}$, various noninvasive methods have been used to solve or lessen the effects of positive pressure MV on BPF, most of them consisting of different methods of pressurizing the chest drainage flask. However, no controlled clinical study or trial has been documented.

The aim of this study was to describe a new adjustable inspiratory occlusion valve (aIOV) used to reduce the deleterious effects caused by BPF, acting directly on the air leakage, improving pulmonary ventilation and blood gases, but without causing hemodynamic derangements.

\section{Methods}

This study was approved by the Ethics Committee on Animal Experimentation of the Institute of Biology, Universidade de Campinas (Protocol no 1685-1 A).

We used six large white pigs weighing $25 \mathrm{~kg}$ each which, after general anesthesia, underwent endotracheal intubation $(6 \mathrm{~mm})$, and mechanically ventilation. The endotracheal tube and the mechanical ventilator circuit were connected through the sensor of volumetric capnography $\left(\mathrm{CO}_{2} \mathrm{SMO}\right.$ Plus DX-8100 ${ }^{\circledR}$ Dixtal/ Novametrix), which was calibrated before the beginning of each experiment. The software (APlus ${ }^{\mathrm{O}}$ ) used to capture and store data online and offline enabled the measurement (in $\mathrm{mL}$ ) of BPF output, which was calculated by subtracting the expired volume (Ve) from the inspired volume (Vi). The percentage of fistula output was defined as the result of this subtraction ( $\mathrm{Vi}$ - Ve) divided by the Vi.

The respiratory rate, tidal volume and $\mathrm{F}_{\mathrm{I}} \mathrm{O}_{2}$ in the $\mathrm{MV}$ remained the same throughout the experiment and was possible observed an increase in $\mathrm{PaCO}_{2}$ and slightly decrease in $\mathrm{PaO}$, but not statistically significant, probably resulting from alveolar hypoventilation.

A pulmonary artery catheter (PAC) was introduced through the femoral vein. Mean arterial pressure (MAP) was recorded continuously (Multiparameter Monitor Dixtal DX-2020; AJIBP-0). Data from arterial and venous blood gases and hemooximetry were collected before (baseline), after creation of BPF and after each experimental setting.

The animals received a continuous infusion of saline $(0.9 \%)$ as well as anesthetics, sedatives and neuromuscular blockers as needed.

\section{Surgical procedure}

Through a left thoracotomy, a resection of the lingula was performed leaving the bronchial stump open in order to create a BPF with an output exceeding $50 \%$ of the inspired volume. The chest cavity was closed and drained into the water sealed system for initial observation of the high output BPF (Figure 1).

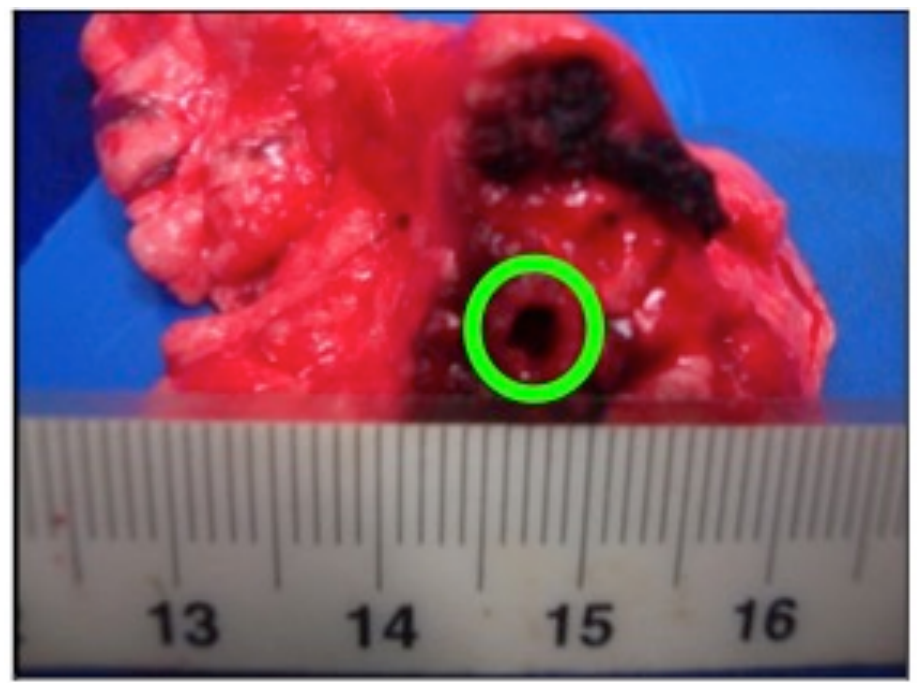

FIGURE 1 - Adjustable inspiratory occlusion valve (aIOV). 
This device, called adjustable inspiratory occlusion valve (deposit number BR 1020120211432 and BR 132013 0320985 patents), which must be connected to the outer extremity of the chest drain, consists of a nipple valve upon which a flexible diaphragm has been superimposed. The diaphragm is activated by proximal pressure (pressure generated in the respiratory system) via a flexible tube connected to the terminal "Y" of the patient (inspiratory pathway). Depending on the size of the nozzle and of the diaphragm, there is a 1:2 relationship between the proximal pressure and the closing pressure of the drain. That is, when the proximal pressure is $10 \mathrm{cmH}_{2} \mathrm{O}$, the occlusion pressure in the drain is $20 \mathrm{cmH}_{2} \mathrm{O}$. In order to allow finer adjustments in the occlusion pressure, we used a needle valve that allowed for a controlled escape flow. The larger the proximal escape flow, the lower the working pressure of the diaphragm. This way, we were able to perform appropriate adjustments in the release pressure of the chest drain, preventing unwanted pressurization of the pleural space. In short, this device is a pressure-stabilizing valve that keeps the pleural pressure slightly below the intrapulmonary pressure, reducing the fistula outflow and allowing for the controlled clearance of pleural air, thus preventing the creation of a tension pneumothorax. The pressure gradient is expected to be 2 to $3 \mathrm{cmH}_{2} \mathrm{O}$ (Figure 2).

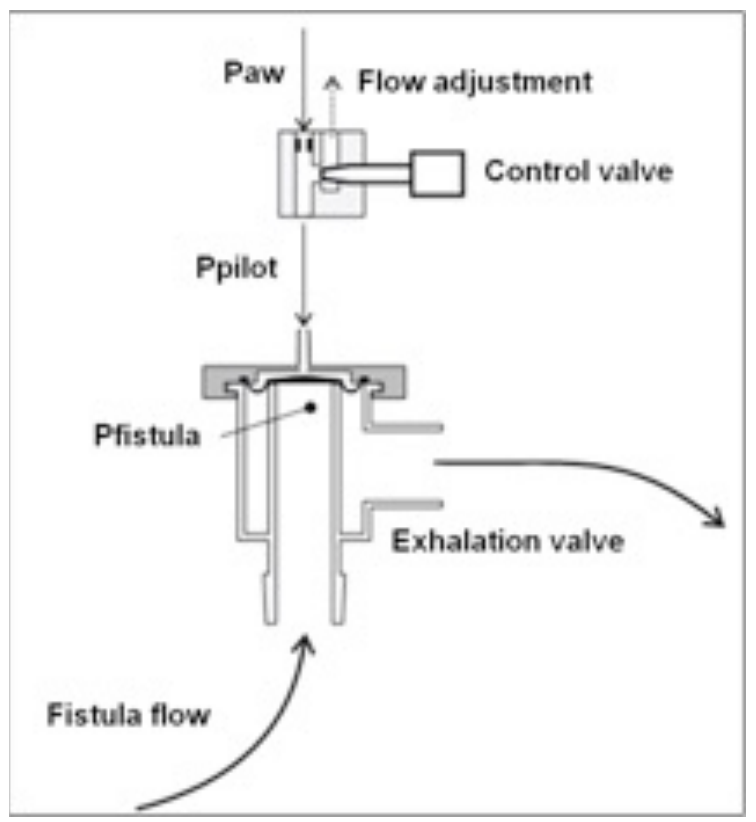

FIGURE 2 - Experimental protocol of mechanical ventilation.
The MV protocol consisted of Volume Controlled Ventilation (VCV), with a Tidal Volume $\left(\mathrm{V}_{\mathrm{T}}\right)$ of $8 \mathrm{ml} / \mathrm{Kg}$, Fraction of Inspired Oxygen $\left(\mathrm{F}_{\mathrm{I}} \mathrm{O}_{2}\right)$ of 0.21 , Inspiratory time versus Expiratory time $(\mathrm{I}: \mathrm{E}$ ratio) $=1: 2$, Respiratory Rate $(\mathrm{RR})$ of 22 bpm, Positive End Expiratory Pressure (PEEP) of $5 \mathrm{cmH}_{2} \mathrm{O}$. Using these ventilatory parameters, it was possible to maintain the end-tidal $\mathrm{CO}_{2}\left(\mathrm{PetCO}_{2}\right)$ around $45 \mathrm{mmHg}$.

Data from arterial blood gases were collected before (baseline), after creation of BPF and after each experimental treatment. A treatment was defined as a 10-minute period of ventilation with the adjustable inspiratory occlusion valve (aIOV) set in different aleatory positions of bronchopleural fistula output (BPFO) from highest to lowest rate of fistula. The treatment 0 corresponds to simple water-sealed drainage of the thorax. There were four treatments with the valve regulated, aleatorialy, in different percentages of BFPO: Treatment 1 (corresponding to $69.6 \pm 20.0 \%$ of BPFO); Treatment 2 - corresponding to $61.0 \pm 19.5 \%$ of BPFO); Treatment-3 (corresponding to $16.8 \pm 10.1 \%$ of BPFO); Treatment 4 - valve in the closed position (corresponding to $9.7 \pm 6.2 \%$ of BPFO).

A statistical analysis was performed for comparison of the continuous variables Cardiac Output (CO), Bronchopleural fistula Output (BPFO), Mean Arterial Pressure (MAP), End Tidal $\mathrm{CO}_{2}\left(\mathrm{PetCO}_{2}\right)$, Arterial Partial Pressure of $\mathrm{O}_{2}\left(\mathrm{PaO}_{2}\right)$, Arterial Partial Pressure of $\mathrm{CO}_{2}\left(\mathrm{PaCO}_{2}\right)$, Arterial Oxygen Saturation $\left(\mathrm{SaO}_{2}\right)$, and Alveolar Tidal Volume $\left(\mathrm{V}_{\mathrm{T}}\right.$ alv $)$ between treatments that began with the water seal and progressed with the use of the valve until it was almost completed closed.

The statistical analysis was carried out comparing only treatments 0 to 4 using analysis of variance, considering each pig as an experimental block. Fixed the significance level at $5 \%$, if the p-value is significant, then at least one pair of treatments has statistical different means. To check if there is difference between two treatments, a Tukey's honest difference test was performed.

\section{Results}

The results of changes in ventilation and hemodynamic recorded in pre-fistula (baseline) and after the creation of the BPF (treatments 0, 1, 2, 3 and 4) and the p-value correspondent to the ANOVA for comparison of the treatments 0 to 4 are arranged in Table 1 . 
TABLE 1 - Data of volumetric capnography, arterial blood gas and hemodynamic variables expressed as mean and standard deviation.

\begin{tabular}{|c|c|c|c|c|c|c|c|}
\hline & Baseline & Treatment 0 & Treatment 1 & Treatment 2 & Treatment 3 & Treatment 4 & p-value \\
\hline $\mathrm{PetCO}_{2}$ & $43.2 \pm 1.8$ & $51.0 \pm 9.5$ & $51.3 \pm 9.4$ & $55.7 \pm 12.7$ & $54.5 \pm 12.2$ & $52.0 \pm 11.5$ & 0.7042 \\
\hline $\mathrm{V}_{\mathrm{T}}$ alv & $173.5 \pm 34.9$ & $\begin{array}{c}92.0 \pm 25.7 \\
a, b\end{array}$ & $\begin{array}{c}55.0 \pm 25.4 \\
\mathrm{c}, \mathrm{d}\end{array}$ & $\begin{array}{c}60.6 \pm 28.8 \\
\text { e,f }\end{array}$ & $\begin{array}{c}139.3 \pm 36.0 \\
\text { a,c,e }\end{array}$ & $\begin{array}{c}156.0 \pm 29.1 \\
\text { b,d,f }\end{array}$ & $<0.0001$ \\
\hline Sat.O $_{2}$ & $88.6 \pm 7.1$ & $68.9 \pm 23.9$ & $51.9 \pm 22.7$ & $54.6 \pm 24.5$ & $56.6 \pm 23.4$ & $57.8 \pm 25.4$ & 0.0992 \\
\hline MAP & $86.7 \pm 17.6$ & $115.2 \pm 19.5$ & $128.2 \pm 20.5$ & $125.5 \pm 22.1$ & $118.0 \pm 9.2$ & $112.8 \pm 13.2$ & 0.3038 \\
\hline $\mathrm{CO}$ & $3.7 \pm 0.8$ & $\begin{array}{c}4.0 \pm 0.9 \\
\mathrm{a}\end{array}$ & $\begin{array}{c}4.9 \pm 1.6 \\
\mathrm{a}, \mathrm{b}\end{array}$ & $4.4 \pm 1.2$ & $4.1 \pm 1.2$ & $\begin{array}{c}3.8 \pm 1.1 \\
\mathrm{~b}\end{array}$ & 0.0138 \\
\hline
\end{tabular}

BPFO (\%): Bronchopleural fistula output; $\mathrm{PetCO}_{2}(\mathrm{mmHg})$ : pressure of end-tidal $\mathrm{CO}_{2} ; \mathrm{PaCO}_{2}(\mathrm{mmHg})$ : partial pressure of $\mathrm{CO}_{2}$ in arterial blood; $\mathrm{V}_{\mathrm{T}}$ alv $(\mathrm{ml})$ : alveolar tidal volume; $\mathrm{PaO}_{2}(\mathrm{mmHg})$ : partial pressure of $\mathrm{O}_{2} ; \mathrm{Sat}_{2}$ (\%): oxygen saturation in arterial blood; $\mathrm{MAP}(\mathrm{mmHg})$ : mean arterial pressure; $\mathrm{CO}$ (L/min): cardiac output. NP: not performed (baseline)

The significant differences between two treatments by Tukey's test are represented by the same letters below their means. Fistula output: Treatment 0 when compared to treatments 1 and 2 resulted in statistically significant increase in the fistula output (Tukey, $\mathrm{p}=0.0001 ; \mathrm{p}=0.0071$, respectively), however the treatment 0 when compared to treatments 3 and 4 resulted in statistically significant decreased in the fistula output (Tukey, $\mathrm{p}=0.0003$ and $\mathrm{p}<0.0001$; respectively).

Arterial partial pressure of $\mathrm{CO}_{2}$ : In treatments 1 to 4 there was observed greater values of $\mathrm{PaCO}_{2}$ when compared to treatment 0 (Tukey; $\mathrm{p}=0.0008 ; \mathrm{p}=0.0002 ; \mathrm{p}=0.0109$ and $\mathrm{p}=0.0135$, respectively).

Alveolar volume: Treatments 3 and 4 presented statistically greater values when compared to treatment 0 (Tukey; $\mathrm{p}=0.0083$ and $\mathrm{p}=0.0004$, respectively).
Arterial partial pressure of $\mathrm{O}_{2}$ and oxygen saturation: The values observed in treatments 1 to 4 are smaller than treatment 0 , but not significant. (ANOVA for $\mathrm{PaO}_{2}$ and $\mathrm{Sat}_{2}$ respectively: $\mathrm{p}=0.0836$ and $\mathrm{p}=0.0992$; Table 1 ).

Mean arterial pressure: There is no significant difference between treatments 0 to 4 (ANOVA $p=0.3038$; Table 1 ).

Cardiac output: There is a significant increase from treatment 0 to treatment 1 (Tukey, $\mathrm{p}=0.0472$ ). However, there are no significant decreases between treatments 1 to 4 when compared to treatment 0 .

The Figure 3 displays a representative model of volumetric capnography curves, during the respective treatments: water seal (0), 1, 2, 3 and 4. Note the significant improvement of the alveolar volume during the treatments.

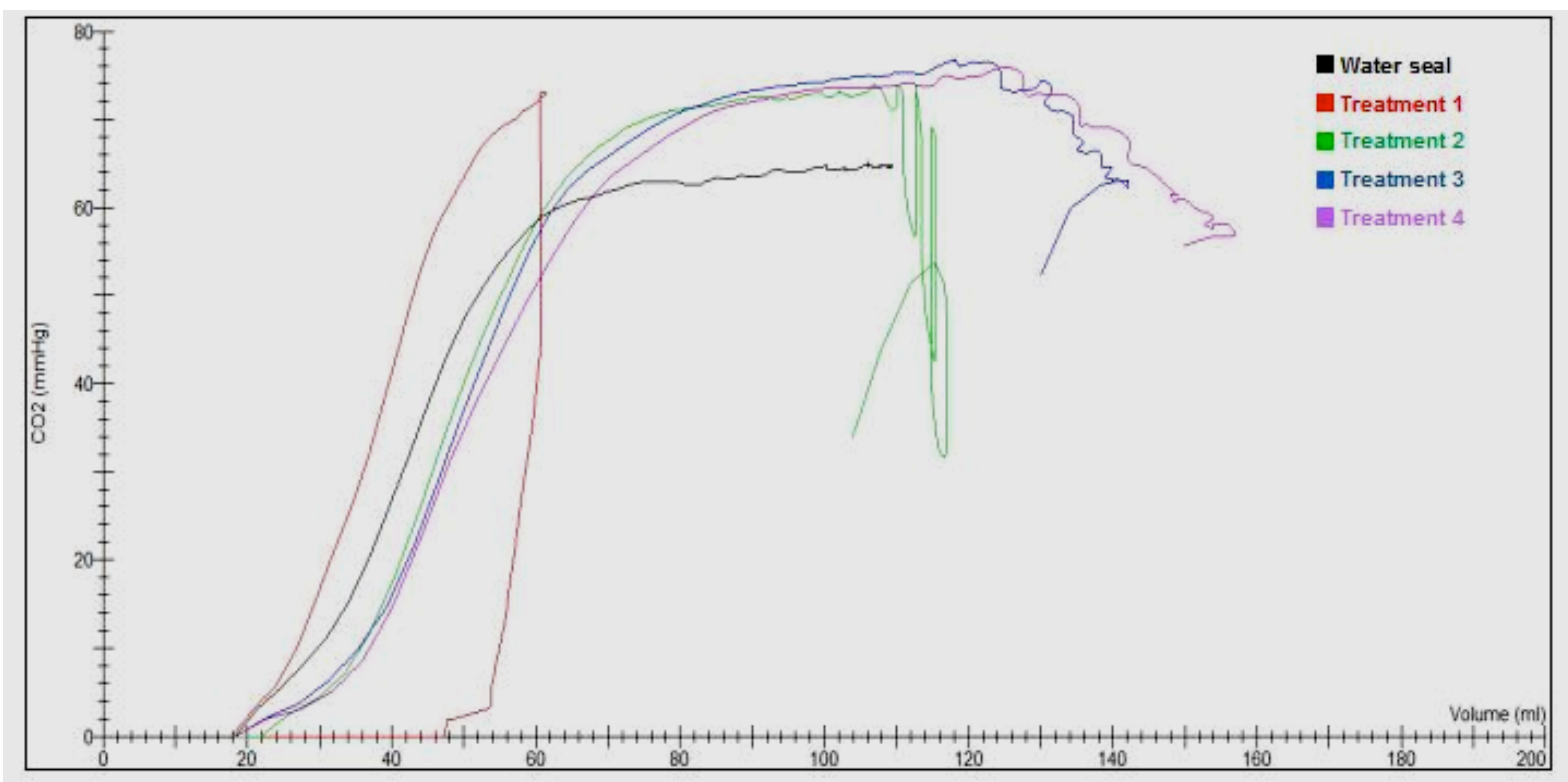

FIGURE 3 - Representative figure of Volumetric Capnography during treatments. In the " $x$ " axis, tidal volume $(\mathrm{mL})$ and the "y" axis, end-tidal $\mathrm{CO}_{2}(\mathrm{mmHg})$. Note that alveolar volume behaves better during treatments 3 and 4 . 


\section{Discussion}

Despite the need to reduce morbidity and mortality of BPF therapy, particularly when associated with mechanical ventilation, little has been advanced in this field in the last decades. This study proposes a new method of reducing the output of a surgically created broncho-pulmonary fistula during mechanical ventilation, that improves alveolar volume, and, most importantly, does not cause any decrease in cardiac output or mean arterial blood pressure when compared with conventional water sealed drainage. The increased in cardiac output between Treatment 0 and 1 is probably due to the fact of increased preload and decreased after load of right ventricle (Table 1).

Several studies have described strategies to control BPF output during MV. However, these studies are mostly case reports and reviews, which failed to present an adequate solution to complications such as pneumothorax, hemodynamic instability, persistent air leak and severe hypoxemia. Published studies describe various forms of treatment, such as pressurization methods ${ }^{8,9}$ ventilatory strategies and surgical techniques such as stent placement in the bronchial tree to try to stop the leak ${ }^{10-12}$. This demonstrates the heterogeneous nature of the problem and partially explains the non-standardization of therapy in BPF.

According to the majority of authors, the ideal treatment of BPF should not include the use of positive pressure ${ }^{1,8}$. However, this is often necessary, especially in cases of high output $\mathrm{BPF}^{4,8,13}$.

The increased mortality in patients with BPF under $\mathrm{MV}$ is the result of hypoventilation and consequent hypoxia. Minimizing the effects of air leakage while maintaining adequate arterial oxygenation may represent a conflicting demand imposed on $\mathrm{MV}^{1}$.

Accordingly, we have developed an Adjustable Inspiratory Occlusion Valve (aIOV) that aims to treat high output BPF in patients undergoing positive pressure MV, specifically by reducing fistula output and improving ventilation without compromising hemodynamic parameters. In this study we have tried to measure its efficacy in pigs having a surgically created, high output BPF.

The assessment of efficacy was performed by volumetric capnography, a method that simplifies control of the ventilation by providing real-time, bedside data for alveolar ventilation. The volumetric capnography is widely applied in other diseases such as $\mathrm{COPD}^{14,15}$, cystic fibrosis and noncystic fibrosis bronchiectasis ${ }^{16-18}$, asthma $^{19}$, pulmonary embolism ${ }^{20-26}$.

Each step of the experiment was conducted for no more than ten minutes, in order to avoid the hypoxia, hypercapnia and hemodynamic instability that were observed during the pilot study, when this time was extended. Mainly, because we did not increase inspiratory fraction of oxygen. It is believed that those problems were secondary to the high output BPF itself, and not to other methodological factors such as surgical incision or surgical time ${ }^{27}$. Leite et al. ${ }^{28}$, using an experimental model of lung re-expansion after bronchial occlusion, found an acute lung inflammatory response, which has been shown to be more pronounced in long periods of bronchial occlusion in terms of cytokine inflammatory response. In addition, the magnitude of this inflammatory response also can be detected systemically ${ }^{28,29}$.

In the present study we did not try, to establish a valve setting that would apply to every case of BPF under MV. Instead we believe that the use of volumetric capnography, by providing respiratory mechanics data in real time, allows for customization of the valve setting to each patient, expressing the individualized character of this therapy. It is however clear by the data presented that higher settings of the valve were associated with a better recovery of the respiratory mechanics.

Arterial blood gas analysis did not show the same behavior as alveolar ventilation. A possible explanation lies in the fact that the time between treatments (10 minutes) and the cumulative effect of previous treatments, might have not allowed complete normalization of the blood gases. In the present experiment, the $\mathrm{F}_{\mathrm{I}} \mathrm{O}_{2}$ was kept at 0.21 , in order to investigate the actual effectiveness of the method under atmospheric conditions. It is noticeable however that, the use of the valve was not associated with any significant worsening of oxygenation when compared to treatment with water seal.

Several strategies have been tried to treat patients with high output BPF needing MV. Oliveira et al. ${ }^{30}$ using an experimental model of high output BPF demonstrated that a simple insertion of a water-sealed thoracic drain resulted in reduction in bronchopleural fistula output and better $\mathrm{CO}_{2}$ clearance without any drop in cardiac output or significant changes in mean arterial pressure. Shekar et al. ${ }^{4}$ maintained the airway pressure below the opening pressure of the BPF, and then optimized the pleural suction pressure thus preventing aggravations. Additionally, Kempainem and Pierson ${ }^{3}$ considered the use of low tidal volume and increased inspiratory/expiratory ratio, as a protective strategy of FBP under VM, because it reduces the peak pressure and avoids auto-PEEP. These authors proposed, in order to reduce the output of the FBP, the use of minimal levels of expiratory pressure, short inspiratory time, low tidal volume and low frequency ${ }^{4}$.

Other ventilatory strategies include high frequency MV (HFMV), which improves alveolar ventilation with consequent 
increase in arterial oxygen saturation, and independent lung ventilation by selective intubation ${ }^{3,4}$.

Although some publications show clear benefits of $\mathrm{HFV}$, such as better ventilation, lower peak pressure and lower mean airway pressure, this technique is not widely applied and is restricted to specialized centers ${ }^{31}$. Furthermore, there are evidences that gas exchange might not be as satisfactory when the HFV is used in pulmonary diseases that concur with low pulmonary compliance ${ }^{2}$.

Alternative strategies such as the occlusion of the chest tube may preserve the PEEP and reduce air leakage during inspiration, while allowing air to escape during the expiratory phase. This can be used in combination with the application of PEEP in the chest tube. Although these measures may help to maintain a small difference in transpulmonary pressure and reduce the risk of pulmonary collapse, they might also compromise the drainage of the pleural cavity and should be used with caution.

Some authors suggest the use of the suction of the drainage flask. However, the negative pressure applied to the chest tube to assist in drainage of the pleural space may increase transpulmonary pressure, resulting in an increase in the fistula output $\mathrm{t}^{3,4}$.

In patients with significant comorbidities or poor response to conservative treatment, non-surgical interventions to decrease the leak may provide temporary treatment, while the patient is stabilized for surgery ${ }^{3,4}$.

Given the difficulties presented by the lack of standardized therapy to treat patients with BPF under MV and it's high mortality in the ICU, this study recommends a strategy that might be used in the presence of acute respiratory disorders arising from the fistula, to avoid additional complications while awaiting for better clinical conditions, that would permit surgical closure of fistula. Maung and Kaplan ${ }^{32}$ reported that patients with injuries such as BPF, require mechanical ventilation to control not only the primary respiratory failure, but also as a complement to manage other conditions.

According to Shekar et al. ${ }^{4}$, the success of therapy in cases of BPF will require strategies tailored to the individual patient needs. Accordingly, the method in question (volumetric capnography and occlusion valve), besides demonstrating the effectiveness of this valve, includes the concept of individualized therapy. In summary, this study demonstrated that it is possible, with the use of the adjustable inspiratory occlusion valve (aIOV), to reduce the leak of a BPF, with consequent improvement in alveolar volume, without compromising hemodynamic parameters, making this device a promising therapeutic tool for the treatment of BPF in patients on
MV. The aIOV accepts different settings, going from 100\% closed to $100 \%$ open, allowing it to be customized, in real time, to the hemodynamic needs and blood gases of the particular patient.

\section{Conclusion}

The occlusion valve decreased the bronchopulmonary fistula output, improved alveolar volume, without compromising the hemodynamic status when compared with conventional treatment (simple water-seal drainage).

\section{References}

1. Pierson DJ, Horton CA, Bates PW. Persistent bronchopleural air leak during mechanical ventilation. Chest. 1986;90(3):321-3. doi: 10.1378/chest.90.3.321.

2. Bishop MJ, Benson MS, Sato P, Pierson DJ. Comparison of highfrequency jet ventilation with conventional mechanical ventilation for bronchopleural fistula. Anesth Analg. 1987;66:833-8. PMID: 3304022.

3. Kempainen RR, Pierson DJ. Persistent Air leaks in patients receiving mechanical ventilation. Semin Respir Crit Care Med. 2001;22(6):675-84. PMID: 16088712.

4. Shekar K, Foot C, Fraser J, Ziegenfuss M, Hopkins P, Windsor M. Bronchopleural fistula: an update for intensivists. J Crit Care. 2010;25:47-55. doi: 10.1016/j.jcrc.2009.05.007.

5. Baumann M, Sahn S. Medical management and therapy of bronchopleural fistulas in the mechanically ventilated patient. Chest. 1990;97:721-8. PMID: 2407455.

6. Martins WR, Siefkin AP, Allen R. Closure of a bronchopleural fistula with bronchoscopic instillation of tetracycline. Chest. 1991;99:1040-2. PMID: 2009764.

7. Spinale FG, Linker RW, Crawford FA, Reines HD. Conventional versus high frequency jet ventilation whit a bronchopleural fistula. J Surg Res. 1989;46(2):147-51. PMID: 2493107.

8. Bevelaqua FA, Kay S. A modified technique for the management of bronchopleural fistula in ventilator - dependent patients: a report of two cases. Respir Care. 1986;31(10):904-8. PMID: 2493107.

9. Chaddouk EG. Bronchopleural fistula and mechanical ventilation: a simple technique of management? J Thorac Cardiovasc Surg. 1995;110:1141-3. PMID: 7475145

10. Andreetti C, D'Andrilli A, Ibrahim M, Ciccone AM, Maurizi G, Mattia A, Venuta F, Rendina EA. Effective treatment of postpneumonectomy bronchopleural fistual by conical fully covered selfexpandable stent. Interact Cardiovasc Thorac Surg. 2012;14(4):4203. PMID: 22268070.

11. Bellato V, Ferraloli GM, De Caria DD, Infante MV, Cariboni U, Spoto MR, Alloisio M, Bordone G. Management of postoperative bronchopleural fistula with a tracheobronchial stent in a patient requiring mechanical ventilation. Intensive Care Med. 2010;36:7212. doi: 10.1007/s00134-010-1757-0.

12. Leo F, Solli P, Veronesi G, Galetta D, Petrella F, Gasparri R, Borri A, Spaggiari L. Review on bronchopleural fistula. Did a surgeon review it? Chest. 2006;129:1731-2. PMID: 16778298.

13. Downs JB, Chapman RL. Treatment of bronchopleural fistula during continuous positive pressure ventilation. Chest. 1976;69(3):363-6. PMID: 786563.

14. Qi GS, Gu WC, Yang WL, Xi F, Wu H, Liu JM. The ability of volumetric capnography to distinguish between chronic 
obstructive pulmonary disease patients and normal subjects. Lung. 2014;192(5):661-8. doi: 10.1007/s00408-014-9615-4.

15. Romero PV, Rodriguez B, de Oliveira D, Blanch L, Manresa F. Volumetric capnography and chronic obstructive pulmonary disease staging. Int J Chron Obstruct Pulmon Dis. 2007;2(3):381-91. PMID: 18229577

16. Veronez L, Moreira MM, Soares ST, Pereira MC, Ribeiro MA, Ribeiro JD, Terzi RG, Martins LC, Paschoal IA. Volumetric capnography for the evaluation of pulmonary disease in adult patients with cystic fibrosis and noncystic fibrosis bronchiectasis. Lung. 2010;188(3):263-8. doi: 10.1007/s00408-009-9213-z.

17. Ribeiro MÂ, Silva MT, Ribeiro JD, Moreira MM, Almeida CC, Almeida-Junior AA, Ribeiro AF, Pereira MC, Hessel G, Paschoal IA. Volumetric capnography as a tool to detect early peripheric lung obstruction in cystic fibrosis patients. J Pediatr (Rio J) 2012;88(6):509-17. doi: 10.2223/JPED.2233.

18. Veronez L, Pereira MC, da Silva SM, Barcaui LA, De Capitani EM, Moreira MM, Paschoal IA. Volumetric capnography for the evaluation of chronic airways diseases. Int J Chron Obstruct Pulmon Dis. 2014 Sep 23;9:983-9. doi: 10.2147/COPD.S62886.

19. Almeida CC, Almeida-Junior AA, Ribeiro MA, Nolasco-Silva MT, Ribeiro JD. Volumetric capnography to detect ventilation inhomogeneity in children and adolescents with controlled persistent asthma. J Pediatr (Rio J). 2011;87(2):163-8. doi: doi:10.2223/ JPED.2077.

20. Moreira MM, Terzi RG, Cortellazzi L, Falcao AL, Moreno H, Jr., Martins LC, Coelho OR. Volumetric capnography: in the diagnostic work-up of chronic thromboembolic disease. Vasc Health Risk Manag. 2010;6:317-9. PMID: 20531949.

21. Pereira DJ, Moreira MM, Paschoal IA, Martins LC, Metze K, Moreno Junior H. Near-fatal pulmonary embolism in an experimental model: hemodynamic, gasometric and capnographic variables. Rev Bras Cir Cardiovasc. 2011;26(3):462-8. PMID: 22086585

22. Moreira MM, Terzi RG, Pereira MC, Grangeia Tde A, Paschoal IA. Volumetric capnography as a noninvasive diagnostic procedure in acute pulmonary thromboembolism. J Bras Pneumol. 2008;34(5):328-32. PMID: 18545830.

23. Moreira MM, Terzi RG, Paschoal IA, Martins LC, Oliveira EP, Falcao AL. Thrombolysis in massive pulmonary embolism based on the volumetric capnography. Arq Bras Cardiol. 2010;95(4):e97-e9. PMID: 21180783

24. Ferreira JH, Terzi RG, Paschoal IA, Silva WA, Moraes AC, Moreira MM. Mechanisms underlying gas exchange alterations in an experimental model of pulmonary embolism. Braz J Med Biol Res. 2006;39(9):1197-204. PMID: 16981047.

25. Moreira MM, Terzi RG, Carvalho CH, de Oliveira Neto AF, Pereira MC, Paschoal IA. Alveolar dead space and capnographic variables before and after thrombolysis in patients with acute pulmonary embolism. Vasc Health Risk Manag. 2009;5(1):9-12. PMID 19436653

26. Moreira MM, Terzi RG, Vieira RW, Petrucci Junior O, Paschoal IA, Oliveira PP, Vilarinho KA, Braile DM. Pre and post-pulmonary thromboendarterectomies capnographic variables. Rev Bras Cir Cardiovasc. 2007;22(4):509-12. PMID: 18488123.

27. Bellenger CR, Hunt GB, Goldsmid SE, Pearson MRB. Outcomes of thoracic surgery in dogs and cats. Am Vet J. 1996;74:25-30. PMID: 8894000

28. Leite CF, Calixto MC, Toro IFC, Antunes E, Mussi RK. Characterization of pulmonary and systemic inflammatory responses produced by lung re-expansion after one-lung ventilation. J Cardiothorac Vasc Anesth. 2012;26(3):427-32. doi: 10.1053/j. jvca.2011.09.028.
29. Wood JG, Johnson JS, Mattioli LF, Gonzalez NC. Systemic hypoxia increases leukocyte emigration and vascular permeability in conscious rats. J Appl Physiol (1985). 2000;89:1561-8. PMID: 11007596.

30. Oliveira DG, Toneloto MG, Moreira MM, Bustorff-Silva JM, Souza GF, Martins LC, Kosour C, Dragosavac D, Falcão AL. Hemodynamic, ventilatory and gasometric evaluation of an experimental bronchopleural fistula. Acta Cir Bras. 2015;30(1):1-5. doi: 10.1590/S0102-86502015001000001.

31. Ihra G, Gockner G, Kashanipour A, Aloy A. High-frequency jet ventilation in European and North American institutions: developments and clinical practice. Eur J Anaesthesiol. 2000;17(7):418-30. PMID: 10964143.

32. MaungAA, Kaplan LJ. Mechanical ventilation after injury. J Intensive Care Med. 2014;29(3):128-37. doi: 10.1177/0885066612457339.

\section{Acknowledgements}

To the team of the Center for Experimental Medicine and Surgery, Faculty of Medical Sciences, UNICAMP, especially to biologists Willian Adalberto Silva and Ana Cristina Moraes.

\section{Correspondence:}

Maria Gabriela Cavicchia Toneloto

Hospital de Clínicas, UNICAMP

Rua Vital Brasil, 251

13083-888 Campinas - SP Brasil

mgabicavi@hotmail.com

Received: Apr 11, 2015

Review: June 14, 2015

Accepted: July 152015

Conflict of interest: none

Financial source: FAPESP (Process $n^{\circ} 04610-2 / 2009$ )

${ }^{1}$ Research performed at Center for Experimental Medicine and Surgery, Faculty of Medical Sciences, Universidade de Campinas (UNICAMP), Brazil. 